\title{
Construction of Spectral Discoloration Model for Red Lead Pigment by Aging Test and Simulating Degradation Experiment
}

\author{
Jinxing Liang, Xiaoxia Wan, Chan Li, Junfeng Li, Qiang Liu, and Qian Cao \\ School of Printing and Packaging, Wuhan University, Wuhan 430079, China \\ Correspondence should be addressed to Xiaoxia Wan; wan_whu@hotmail.com
}

Received 28 May 2016; Revised 26 July 2016; Accepted 3 August 2016

Academic Editor: Austin Nevin

Copyright (C) 2016 Jinxing Liang et al. This is an open access article distributed under the Creative Commons Attribution License, which permits unrestricted use, distribution, and reproduction in any medium, provided the original work is properly cited.

\begin{abstract}
The construction of spectral discoloration model, based on aging test and simulating degradation experiment, was proposed to detect the aging degree of red lead pigment in ancient murals and to reproduce the spectral data supporting digital restoration of the ancient murals. The degradation process of red lead pigment under the aging test conditions was revealed by X-ray diffraction, scanning electron microscopy, and spectrophotometer. The simulating degradation experiment was carried out by proportionally mixing red lead and lead dioxide with referring to the results of aging test. The experimental result indicated that the pure red lead was gradually turned into black lead dioxide, and the amount of tiny particles of the aging sample increased faced with aging process. Both the chroma and lightness of red lead pigment decreased with discoloration, and its hue essentially remains unchanged. In addition, the spectral reflectance curves of the aging samples almost started rising at about $550 \mathrm{~nm}$ with the inflection moving slightly from about $570 \mathrm{~nm}$ to $550 \mathrm{~nm}$. The spectral reflectance of samples in long- and in short-wavelength regions was fitted well with the logarithmic and linear function. The spectral discoloration model was established, and the real aging red lead pigment in Dunhuang murals was measured and verified the effectiveness of the model.
\end{abstract}

\section{Introduction}

Lead-based pigments have been widely employed and confirmed to exist in various fields of art [1-3]. Among the leadbased pigments, red lead pigment, as the bright one, was chosen by most ancient painters to enrich the tones on a large variety of artworks, including medieval manuscripts [4], wood-block print [5], canvas paintings [6], or wall paintings [7]. In most cases, however, the red lead pigment painted layers have been turned into brown or complete black, which is caused by humidity, light (mainly ultraviolet), gas environment, and other aspects [8-10]. The artistic effect of the ancient artworks was seriously affected by the degradation of red lead pigment, and people could not appreciate the original status of these precious heritages. At the same time, the discoloration of the ancient artworks also hindered the excavation of the historical information about the ancient societies. Thus, it is necessary and valuable to develop the method to digitally recover the darkened artworks to their original status, wherein the restoration of the darkened artworks should be based on the discoloration model and the discoloration model needs to satisfy the principle that the reproduced data are consistent with the real aging red lead pigment on artworks as much as possible.

Modern analysis devices and technique provide the potential to systematically study the degradation process of the red lead pigment and to construct the discoloration models in different aging conditions. Over the past few decades, many researches have focused on revealing the mechanism of red lead degradation $[2,4,5,8,9]$, but only a few studies have been involved in construction of the red lead discoloration model [11-13]. Shi and Lu firstly introduced the colorimetric and chemical models based aging simulation of Dunhuang murals for restoration and for audience reexperiencing the aging process of the murals [11]. And lately, they further formalized the empirical knowledge from artists in their models to improve the simulation results [12]. Recently, Zhao et al. studied the mechanism of red lead degradation and constructed the corresponding time and color functions for the aging process but did not validate the established functions with real aging red lead in murals [13]. The main purpose of constructing the discoloration model is to restore the fading 
artworks to their original colors in correct way. However, current discoloration models for red lead pigment are all based on the colorimetric theory, which were constructed in RGB or Lab color spaces and inevitably influenced by metameric problem [14].

Spectral reflectance, which is robust to illumination and observer variations, is regarded at the "fingerprint" of the object color as the color parameters are calculated from spectral reflectance under any illuminations and observer conditions based on colorimetric theory. At the same time, spectral reflectance also reflects the chemical and physical properties of the object as the absorption/reflectance features of an object depend primarily on the chemical properties of its components and secondly on the physical properties. The technology of spectral imaging developed rapidly in the field of cultural heritages protection for the past decades because of its high-quality imaging abilities and its safety and effectiveness in pigment identification [15-17]. If the spectral discoloration model was constructed for red lead pigment, the virtual restoration of the ancient murals would be more scientific using the spectral images. In this study, the degradation process of red lead pigment in Dunhuang murals was studied by aging test and simulating degradation experiment. The spectral discoloration model of red lead pigment was constructed, and the validity of the model was verified by calculating and predicting the spectral reflectance of the real aging red lead pigment in Dunhuang murals.

\section{Materials and Methods}

2.1. Material. Generally, murals in Dunhuang grottoes consist of four layers: the coarse clay layer, the fine clay layer, the plaster layer, and the pigment layer. The coarse clay layer contains the mixture of straw and sand in an appropriate ratio to fill up the cliff. The fine clay layer contains moderate cotton or flax fibers to fill the cracks of the dry coarse clay layer as a flat plane. The plaster layer is used to cover the fine clay layer for paintings, and the pigment layer is lastly painted on the plaster layer by Chinese goat-hair brush to complete the construction of the wall paintings, in which the pigment is usually dispersed in animal glue (mostly in cowhide glue). In this study, the industrial white cardboard is applied as substrate to simulate the plaster of the murals since the chemical properties of plaster layer are stable. The pure red lead pigment is well-dispersed in the cowhide glue and painted carefully on the substrate layer to create the experimental samples. The pure red lead pigment, the animal gelatin, and the tools painting mural sample were supplied by Dunhuang Academy (Dunhuang, China). In addition, they also imparted the skills of preparing the animal gelatin solution and the techniques of painting the mural sample. The pure lead dioxide used for simulating degradation experiment was purchased from the Shenshi Chemical Co., Ltd. (Wuhan, China).

2.2. Apparatus. The ultraviolet (UV) light and humidity are the main factors causing the discoloration of red lead in Dunhuang murals [8,10-13]. The UV aging experiment box ZN-P with high pressure mercury lamp and the constanttemperature-and-humidity tested box DHS-500 were chosen
TABLE 1: Statistical results of spectral measurement accuracy, repeatability, and consistency of Color-Eye 7000A spectrophotometer and PR705 spectroradiometer.

\begin{tabular}{lccccccc}
\hline & RMS (\%) & Red & Green & Blue & Yellow & Magenta & Cyan \\
\hline \multirow{3}{*}{ 7000A } & Mean & 0.34 & 0.35 & 0.44 & 0.35 & 0.46 & 0.37 \\
& Max & 0.49 & 0.54 & 0.69 & 0.72 & 0.71 & 0.61 \\
& Min & 0.22 & 0.22 & 0.22 & 0.31 & 0.34 & 0.21 \\
\hline \multirow{2}{*}{ PR705 } & Mean & 0.37 & 0.38 & 0.49 & 0.42 & 0.49 & 0.42 \\
& Max & 0.56 & 0.66 & 0.68 & 0.69 & 0.81 & 0.76 \\
& Min & 0.26 & 0.21 & 0.24 & 0.33 & 0.37 & 0.23 \\
\hline \multirow{2}{*}{ PR705 } & Mean & 0.44 & 0.42 & 0.47 & 0.42 & 0.53 & 0.41 \\
versus & Max & 0.79 & 0.81 & 0.78 & 0.82 & 0.85 & 0.78 \\
7000A & Min & 0.36 & 0.34 & 0.37 & 0.32 & 0.39 & 0.36 \\
\hline
\end{tabular}

to carry out the aging test. The wavelength of the high pressure $40 \mathrm{w}$ mercury lamp ranges from 200 to $1400 \mathrm{~nm}$ with the dominant emission wavelength at $365 \mathrm{~nm}$. The humidity and temperature ranges of the two types aging equipment could be controlled at $30 \sim 98 \% \mathrm{RH}$ and $0 \sim 150^{\circ} \mathrm{C}$. The X-ray diffraction (XRD) analyzer Bruker Smart Apex CCDII was adopted to analyze chemical phases of the aging samples. The microstructure analysis of the aging samples was completed using Quanta 200 scanning electron microscope (SEM). The spectral reflectance of the sample ranging from 360 to $750 \mathrm{~nm}$ at $10 \mathrm{~nm}$ intervals was measured using GretagMacbeth X-Rite Color-Eye 7000A spectrophotometer in specular component excluded (SCE) model. Furthermore, the electronic analytical balance METTLER TOLEDO AB135-S/FACT, measurement accuracy of which is $0.01 / 0.1 \mathrm{mg}$, was used to measure the mass of the gelatin and red lead pigment when preparing the gelatin solution and painting a mural sample. The real aging red lead pigment points were measured by the PR705 spectroradiometer with the standard whiteboard produced by Photo Research Inc. (American).

2.3. Spectral Measurement and Color Expression. Prior to the formal experiment, the spectral measurement accuracy and repeatability as well as the consistency between two types of spectral measurement devices were evaluated to ensure the validity of the spectral measurement results. Six saturated standard color samples of GretagMacbeth ColorCkher Chart (red, green, blue, yellow, magenta, and cyan) were used to carry out the evaluation procedure. The root-mean-square error (RMSE) was calculated between the measured spectral and the corresponding certified values. Each measurement was repeated fifty times at the interval of twenty seconds. Statistical results of the accuracy, repeatability, and consistency are summarized in Table 1. The mean RMSE for all the color samples measured by 7000A and PR705 is less than $0.49 \%$ and the maximum RMSE is less than $0.81 \%$. These results indicate that there is good accuracy and repeatability for both spectral measurement devices. The mean and maximum RMSE between $7000 \mathrm{~A}$ and PR705 are $0.53 \%$ and $0.85 \%$, respectively, which is slightly higher than the accuracy and repeatability of each device alone but still maintains a fairly good consistency. 

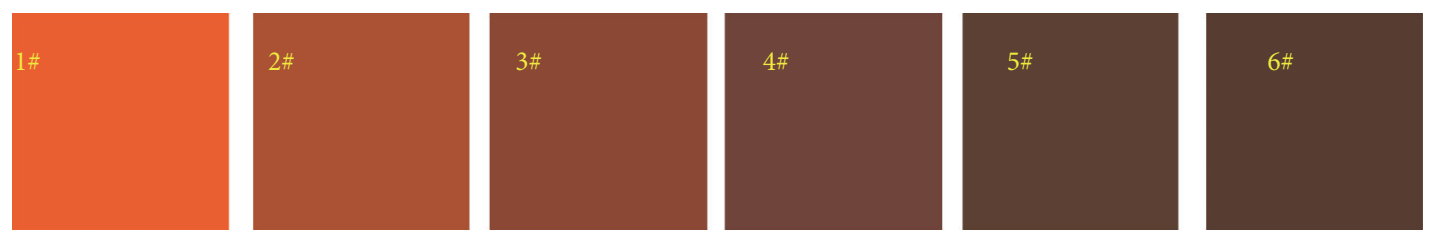

Figure 1: Samples in different aging degrees: 0 days (1\#), 5 days (2\#), 10 days (3\#), 15 days (4\#), 20 days (5\#), and 25 days (6\#).

After the spectral reflectance was acquired, the color parameter of samples was calculated under the CIE standard illuminant D50 and the CIE 1931 standard observer. The spectral reflectance was firstly converted to the CIE $X Y Z$ tristimulus according to (1), where $x(\lambda), y(\lambda)$, and $z(\lambda)$ represent color-matching functions, $E(\lambda)$ represents the spectral power distribution of the CIE standard illuminant, $S(\lambda)$ is the measured spectral reflectance of the samples, and $k$ is the adjustment factor. And then the chromaticity values of the samples like $Y x y, L^{*} a^{*} b^{*}$, or sRGB were calculated from the CIE $X Y Z$ tristimulus, and the transformation from $X Y Z$ to $Y x y, L^{*} a^{*} b^{*}$, and sRGB values can be referenced in the literature [18]:

$$
\begin{aligned}
& X=k \int_{\lambda} x(\lambda) E(\lambda) S(\lambda) d \lambda, \\
& Y=k \int_{\lambda} y(\lambda) E(\lambda) S(\lambda) d \lambda, \\
& Z=k \int_{\lambda} z(\lambda) E(\lambda) S(\lambda) d \lambda,
\end{aligned}
$$

$$
k=\frac{100}{\left[\sum_{\lambda} y(\lambda) E(\lambda) d \lambda\right]} .
$$

Besides, the color of the experiment samples can be presented by Matlab toolbox OptProp as the sRGB values of the samples can be rendered as uniformity color patches by the function of OptImage [19]. The color difference between the samples was calculated by the CIEDE2000 $\left(\mathrm{DE}_{00}\right)$ formula [20].

2.4. Parameters Setting for Aging Test. Six red lead samples were painted for the aging test. The temperature and humidity were settled at the level of $60^{\circ} \mathrm{C}$ and $80 \% \mathrm{RH}$ for the aging tests. The test boxes were maintained in a stable working state. The red lead pigment samples were placed alternately in two test boxes with the interval of 12 hours starting from the constant-temperature-and-humidity test box. From beginning of aging test, one sample was picked out every five days, until the aging test was completed. Samples of 0 days, 5 days, 10 days, 15 days, 20 days, and 25 days were denoted as sample $1(1 \#)$, sample $2(2 \#)$, sample $3(3 \#)$, sample $4(4 \#)$, sample $5(5 \#)$, and sample $6(6 \#)$. Each sample was measured and analyzed using the professional equipment mentioned above. The spectral reflectance of the samples was measured in a constant-temperature-and-humidity optical laboratory with temperature at $25^{\circ} \mathrm{C}$ and humidity at $40 \% \mathrm{RH}$.

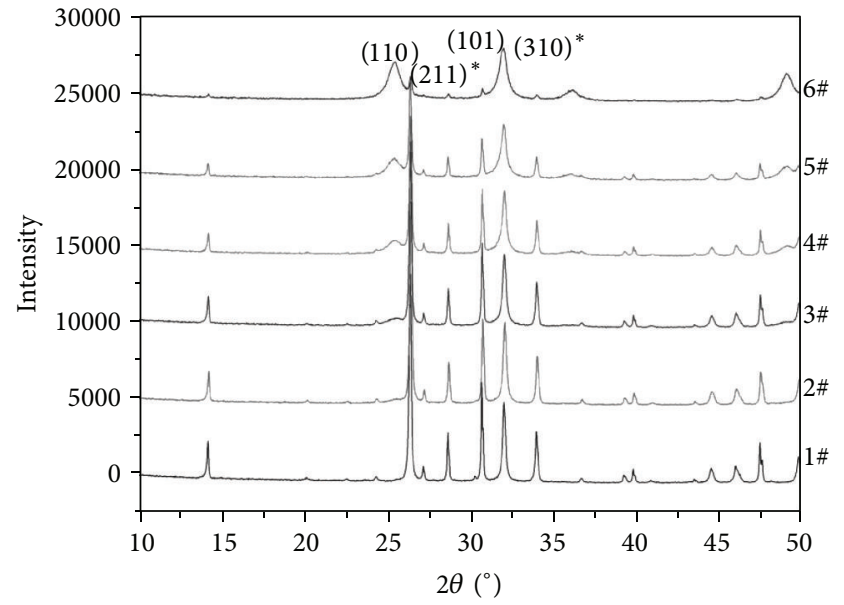

FIGURE 2: XRD results for the aging samples: () represents the diffraction peak of $\mathrm{PbO}_{2}$. ()$^{*}$ represents the diffraction peak of $\mathrm{Pb}_{3} \mathrm{O}_{4}$.

TABLE 2: The diffraction intensity ratio of $\mathrm{PbO}_{2}$ to $\mathrm{Pb}_{3} \mathrm{O}_{4}$ of the aging samples.

\begin{tabular}{lcccccc}
\hline Sample & $1 \#$ & $2 \#$ & $3 \#$ & $4 \#$ & $5 \#$ & $6 \#$ \\
\hline $\begin{array}{l}\text { Intensity ratio } \\
\left(I_{\mathrm{PbO}_{2}} / I_{\mathrm{Pb}_{3} \mathrm{O}_{4}}\right)\end{array}$ & 0 & 0.048 & 0.072 & 0.138 & 0.258 & 1.503 \\
\hline
\end{tabular}

\section{Result and Discussion}

3.1. Aging Test. The color appearance of red lead pigment changed from bright oranges to dim blacks as shown in Figure 1. The difference in color appearance between the two adjacent samples from $1 \#$ to $6 \#$ is gradually getting smaller from visual perception. The detailed information for characterization and analysis of the chemical composition, microstructure, spectral reflectance, and chromaticity values of the aging samples were described in the following parts.

3.1.1. Chemical Composition. As illustrated in Figure 2, XRD results indicated that the aging product of red lead under the aging test environment was lead dioxide, explained by the increased diffraction peaks of $\mathrm{PbO}_{2}$ and the decreased diffraction peaks of $\mathrm{Pb}_{3} \mathrm{O}_{4}$. This is consistent with the previous researches $[2,4,5]$. Furthermore, the diffraction intensity ratio of $\mathrm{PbO}_{2}$ to $\mathrm{Pb}_{3} \mathrm{O}_{4}$ in Table 2 and the discrimination of color between the adjacent samples in Figure 1 indicated the strong color covering power of lead dioxide. A little amount of lead dioxide may darken the sample remarkably, but when 

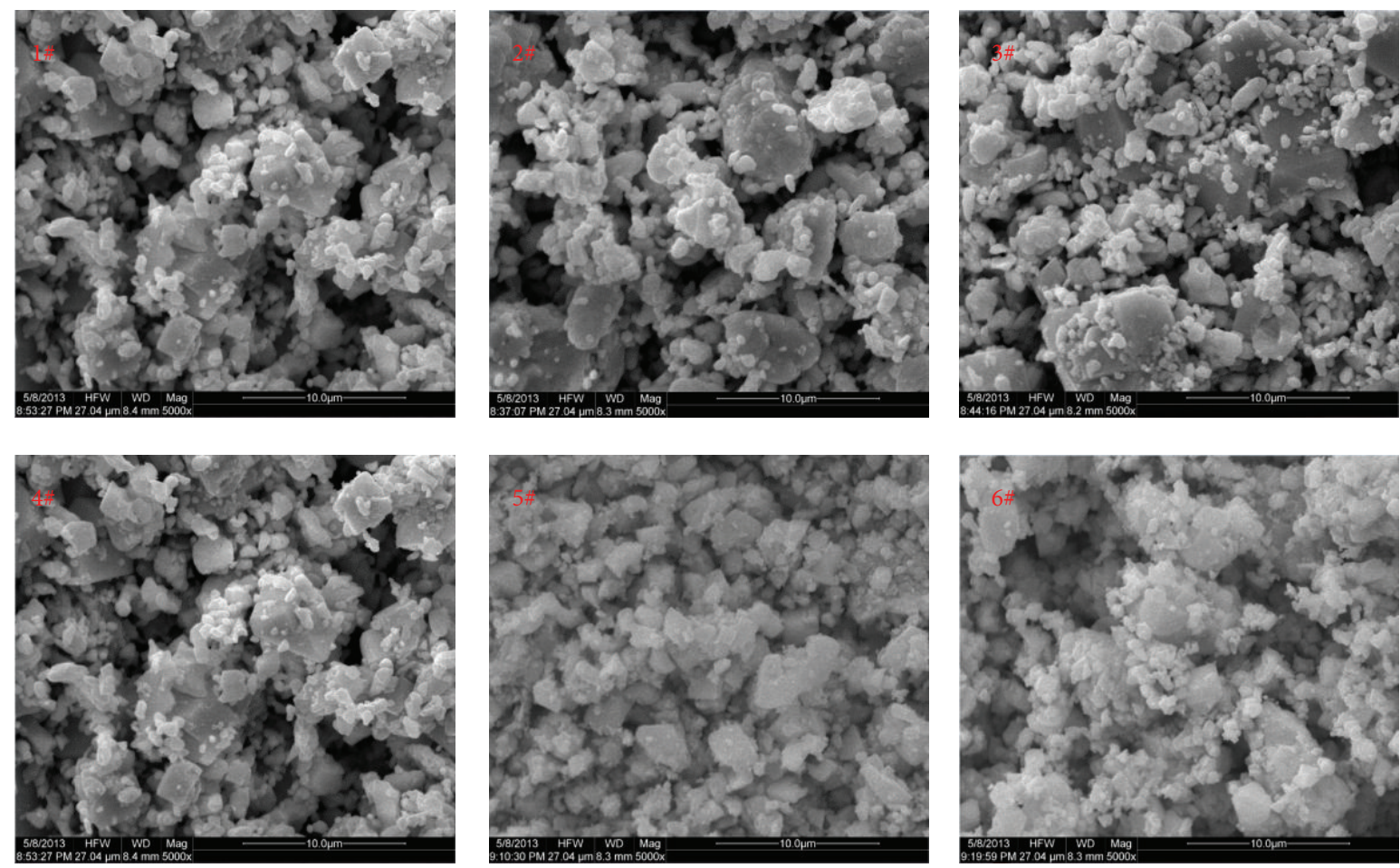

FIgURE 3: Microstructure of the six aging samples.

TABLe 3: Particles distribution of the aging samples.

\begin{tabular}{lcccccc}
\hline Sample & 1\# & 2\# & 3\# & 4\# & 5\# & 6\# \\
\hline $\operatorname{Max} /(\mu \mathrm{m})$ & 8.21 & 5.41 & 3.62 & 2.52 & 2.41 & 2.12 \\
$\operatorname{Min} /(\mu \mathrm{m})$ & 0.63 & 0.5 & 0.4 & 0.38 & 0.21 & 0.21 \\
$\operatorname{Mean} /(\mu \mathrm{m})$ & 2.12 & 1.78 & 1.36 & 1.03 & 0.79 & 0.66 \\
\hline
\end{tabular}

the amount of lead dioxide reaches a certain degree, its color covering ability will reach the maximum.

3.1.2. Microstructure. The microstructure image of the aging samples captured with SEM is shown in Figure 3. It demonstrated that the amount of the large particle is decreasing and the amount of tiny particle is increasing faced with the aging process, but there are still some large particles wrapped by tiny particles. The grain size distribution of the aging samples measured through analysis software was summarized in Table 3. The statistics shows that the maximum, minimum, and mean particle size are reduced as the aging time passes, and the minimum particle size is ultimately stable at the level of $0.21 \mu \mathrm{m}$. Based on the particle size changing trend described above, the minimum particles in the aging samples may be the lead dioxide. The phenomenon of the large particles wrapped by tiny particles may be the reason why the previous researchers observed the incomplete oxidized red lead pigment grains in the cross section of the pigment layer painted by red lead pigment $[7,8]$.

Moreover, the optic path of the incident lights becomes increasingly more complex owing to the reduced large particles and the increased tiny particles of the aging process.
The complexity of the sample's microstructure enhanced the optic path of the incident lights by increasing its frequency of reflection according to light propagation theory. Coupled with the strong light absorption of $\mathrm{PbO}_{2}$, the amount of emergent light was inevitably reduced and the samples dramatically grew darker over aging time as shown in Figure 1.

3.1.3. Spectral Reflectance and Chromaticity. The spectral reflectance of the aging samples was measured with GretagMacbeth X-Rite Color-Eye 7000A spectrophotometer in SCE model. As illustrated in Figure 4(a), the spectral reflectance of the aging samples of long-wavelength from 550 to $750 \mathrm{~nm}$ apparently decreased with the aging time, while the decreased value of the spectral reflectance in the same aging interval becomes smaller and smaller. It is suggested that the darkening trends of samples become slower, but this does not reveal that the chemical composition transition also obeys the same law. The intensity ratio of $\mathrm{PbO}_{2}$ to $\mathrm{Pb}_{3} \mathrm{O}_{4}$ in Table 2 shows that the chemical composition transition rates exhibit a thoroughly inverse trend. The inconsistency between sample darkening trends and chemical composition transition rate from red lead to lead dioxide may be mainly caused by the strong color covering power of lead dioxide and its proportion in the aging samples as described above. According to the spectral reflectance change trends, we preliminary infer that the logarithmic function could be well applied to construct the red lead pigment discoloration model under the aging conditions.

In addition, it was easy to find that the spectral reflectance of the aging samples almost has the same rising point in about $550 \mathrm{~nm}$, and the faint decrease in short-wavelength regions is 


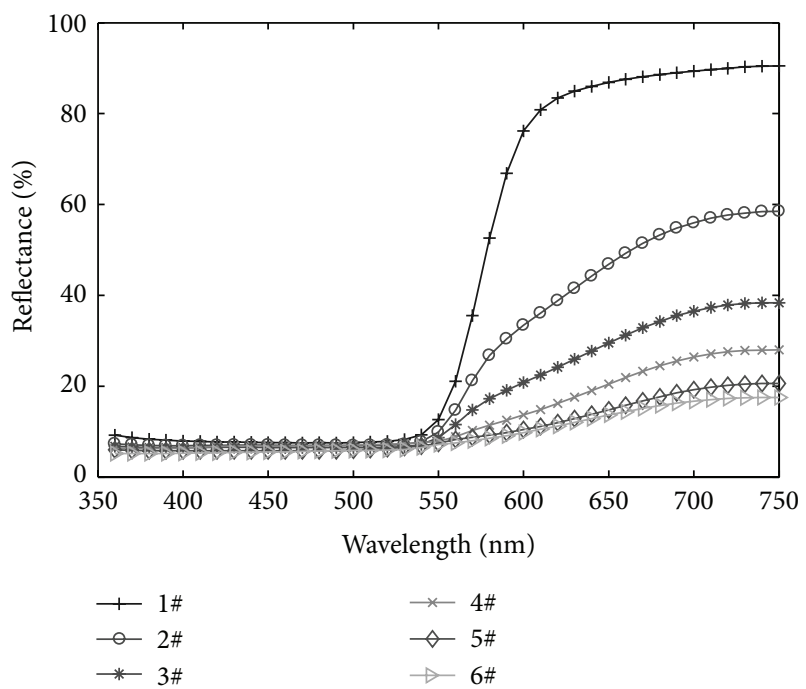

(a)

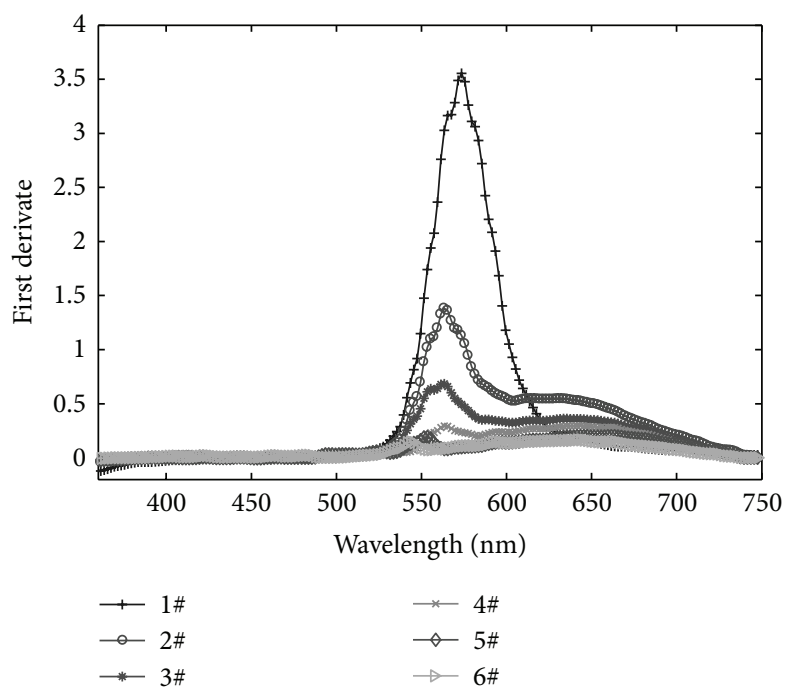

(b)

FIGURE 4: Distribution of the spectral reflectance of the aging samples (a) and the corresponding first derivate (b).

TABLE 4: Chromaticity and color difference of the aging samples.

\begin{tabular}{|c|c|c|c|c|c|c|c|c|c|c|c|c|}
\hline \multirow{2}{*}{ Sample } & \multicolumn{6}{|c|}{ Color coordinate } & \multirow{2}{*}{ Chroma $\left(C^{*}\right)$} & \multirow{2}{*}{$\mathrm{DE}_{00}$} & \multirow{2}{*}{$\Delta L^{*}$} & \multirow{2}{*}{$\Delta a^{*}$} & \multirow{2}{*}{$\Delta b^{*}$} & \multirow{2}{*}{$\Delta \mathrm{DE}_{00}$} \\
\hline & Y & $x$ & $y$ & $L^{*}$ & $a^{*}$ & $b^{*}$ & & & & & & \\
\hline $1 \#$ & 30.935 & 0.577 & 0.371 & 62.452 & 52.263 & 50.530 & 72.71 & 0 & - & - & - & - \\
\hline $2 \#$ & 16.951 & 0.535 & 0.374 & 48.198 & 38.825 & 36.977 & 53.62 & 14.32 & 14.254 & 13.438 & 13.553 & 14.32 \\
\hline $3 \#$ & 11.300 & 0.503 & 0.374 & 40.081 & 28.550 & 25.495 & 38.28 & 24.37 & 8.117 & 10.275 & 11.482 & 10.05 \\
\hline $4 \#$ & 8.241 & 0.474 & 0.367 & 34.479 & 18.997 & 16.983 & 23.59 & 31.44 & 5.602 & 9.533 & 8.512 & 7.07 \\
\hline $5 \#$ & 6.454 & 0.451 & 0.363 & 30.530 & 13.478 & 12.879 & 18.64 & 35.62 & 3.949 & 5.499 & 4.104 & 4.18 \\
\hline 6\# & 5.920 & 0.439 & 0.361 & 29.209 & 12.961 & 12.133 & 17.75 & 36.67 & 1.321 & 0.517 & 0.746 & 1.05 \\
\hline
\end{tabular}

from 360 to $550 \mathrm{~nm}$. As the spectral reflectance of the aging sample is primarily determined by the chemical properties of its components, the spectral features of the aging samples could be explained from the chemical components aspect as the aging samples share the same chemical components except sample 1\#. Red lead absorbs the light from 360 to $550 \mathrm{~nm}$ and reflects the rest in visible light region, while lead dioxide absorbs almost all visible light. The different ratios of red lead and lead dioxide contained in the aging samples lead to the almost same rising point and the low reflection in short-wavelength region. Furthermore, as shown in Figure 4(b), the different ratios of red lead and lead dioxide contained in the aging samples also influence the inflection of the spectral curve. With the amount of lead dioxide increased in the aging samples, the spectral inflection of samples is slightly moved from about 570 to $550 \mathrm{~nm}$.

The chromaticity and color difference of the aging samples were summarized in Table 4 . The brightness value of the aging samples $Y$ and $L^{*}$ as well as the chroma value $C^{*}$ decreased rapidly at the beginning of the experiment, but the speed slows down later in the experiment. Similarly, the color difference $\mathrm{DE}_{00}$ increased rapidly at the beginning of the experiment and the growth slackened later in the experiment. The changing trends of the chromaticity values consisted with the trend of the spectral reflectance in the long-wavelength regions. The reason for such phenomenon was that the chromaticity is linearly calculated from spectral reflectance multiplied by spectral power distributions of the illumination and by color-matching functions [19].

The hue of the aging samples in $a^{*}-b^{*}$ planes and in CIE 1931 chromaticity diagram was plotted in Figure 5, where $a^{*}$ represents the red-green response and $b^{*}$ represents the yellow-blue response from human visual system in CIE $L^{*} a^{*} b^{*}$ uniform color space, respectively. Figure 5(a) indicated that the hue changed trends can be fitted very well with the linear model, and Figure 5(b) shows the same varying tendencies. The values of $\Delta a^{*}, \Delta b^{*}$, and $\Delta L^{*}$ were also summarized in Table 4 , which shows the same changing trends as $\Delta \mathrm{DE}_{00}$. Based on the data changing trends of $\Delta a^{*}$, $\Delta b^{*}, \Delta L^{*}$, and $C^{*}$ in Table 4 and the hue distributions of aging samples plotted in Figure 5, it could be concluded that, during the red lead pigment aging process, the main changing 


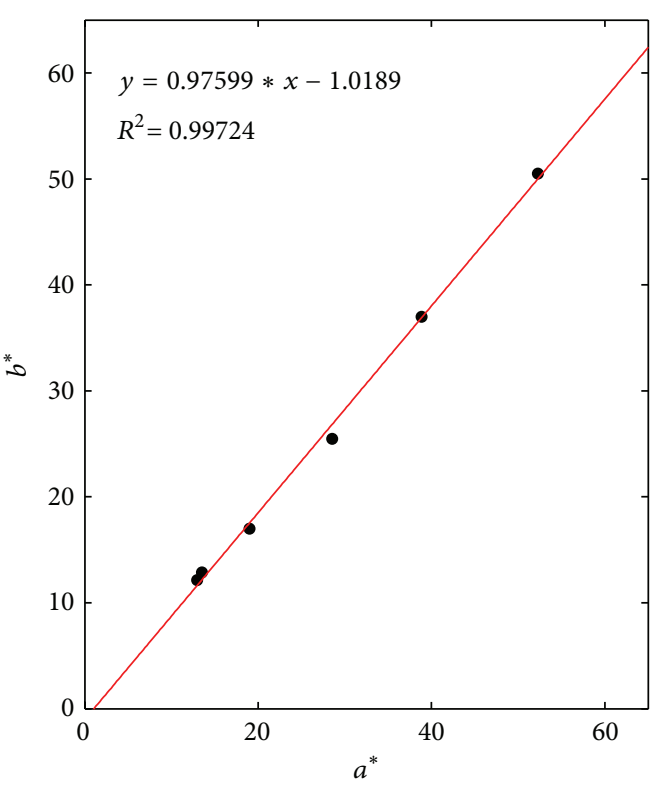

(a)

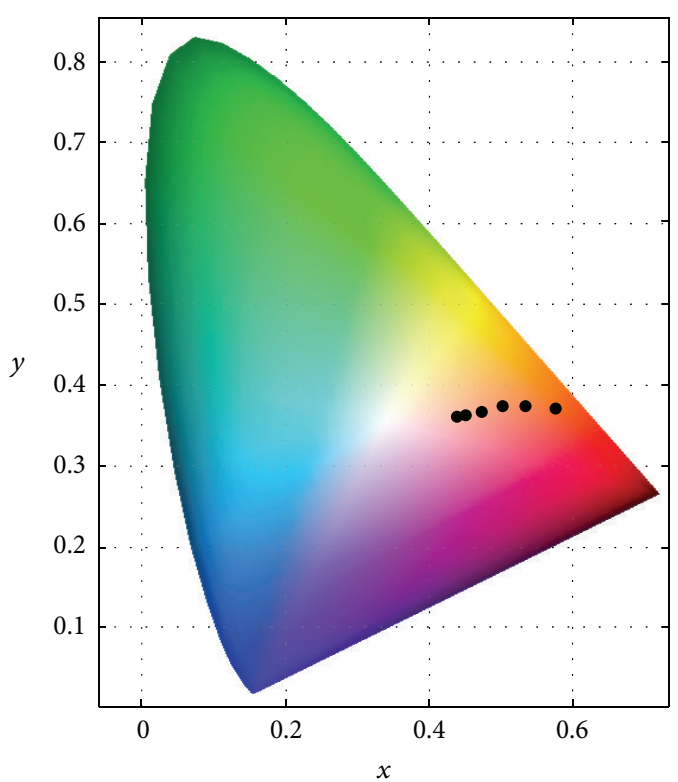

(b)

FIgURE 5: Hues of aging samples in $a^{*}-b^{*}$ planes (a) and CIE 1931 chromaticity diagram (b).

TABLE 5: Names and mixing ratios of the simulating degradation samples.

\begin{tabular}{lccccccccccc}
\hline Sample & $\mathrm{S} 1$ & $\mathrm{~S} 2$ & $\mathrm{~S} 3$ & $\mathrm{~S} 4$ & $\mathrm{~S} 5$ & $\mathrm{~S} 6$ & $\mathrm{~S} 7$ & $\mathrm{~S} 8$ & $\mathrm{~S} 9$ & $\mathrm{~S} 10$ & $\mathrm{~S} 11$ \\
\hline $\mathrm{Pb}_{3} \mathrm{O}_{4} / \mathrm{g}$ & 0.60 & 0.54 & 0.48 & 0.42 & 0.36 & 0.30 & 0.24 & 0.18 & 0.12 & 0.06 & 0.00 \\
$\mathrm{PbO}_{2} / \mathrm{g}$ & 0.00 & 0.06 & 0.12 & 0.18 & 0.24 & 0.30 & 0.36 & 0.42 & 0.48 & 0.54 & 0.60 \\
\hline
\end{tabular}

chromaticity feature was the brightness and chroma value, and the hue of the aging samples almost remains unchanged.

In the next part, the simulating degradation experiment was carried out with referring to the result of aging test. And the spectral reflectance and chromaticity of the aging samples were further analyzed for construction of the spectral discoloration model.

3.2. Simulating Degradation Experiment. In this experiment, eleven experimental samples were painted using the painting method simulating Dunhuang murals. The samples were mixed by red lead and lead dioxide in different mixing ratios with total mass controlled at $0.6 \mathrm{~g}$ as the quantity is enough for painting a sample in this study, and the mass change step of the pure red lead and lead dioxide was set at $0.06 \mathrm{~g}$. The name and the corresponding mixing ratio of the simulating degradation samples are listed in Table 5.

The spectral reflectance of the simulating degradation samples was also measured by GretagMacbeth X-Rite ColorEye 7000A spectrophotometer in SCE model, and the chromaticity of each simulating degradation sample was calculated using Matlab toolbox OptProp. The color of each simulating degradation sample is rendered in Figure 6. The spectral reflectance and the corresponding first derivate of the simulating degradation samples are plotted in Figure 7, and the chromaticity value of the simulating degradation samples is summarized in Table 6.
It indicated that there is a strong similarity between the aging test and simulating degradation experiment about the changing trend of the spectral reflectance, the first derivate of spectral reflectance, and the chromaticity values. However, there is slight difference between the spectral reflectance curves shapes of the two experiments according to the results of gelatin degradation in Dunhuang murals carried out by $\mathrm{Li}$ [21]. The humidity and light are two important factors causing the aging of the gelatin which lead to the gelatin solution from almost transparent status gradually becoming light yellow, so it can be inferred that the slight difference between the spectral reflectance curves shapes may be caused by the aging of the gelatin in the samples. However, the similarity of spectral and chromaticity features of the samples between the aging test and simulating degradation experiment inferred that the aging of the gelatin just has a very small influence on the aging trends of red lead pigment. The hue distribution of the simulating degradation samples in $a^{*}-b^{*}$ planes and CIE 1931 chromaticity diagram was shown in Figure 8. The hue distribution also maintains high similarity with the aging test result as it can be fitted very well using the linear model. The similarity of the two experimental results may also prove that the mechanism of the red lead pigment discoloration in Dunhuang murals is caused by the process of red lead altered in lead dioxide.

3.3. Spectral Discoloration Model Construction. The decreased trend of spectral reflectance in long-wavelength regions of the 
TABLE 6: Chromaticity features of the simulating degradation samples.

\begin{tabular}{|c|c|c|c|c|c|c|c|c|c|c|c|c|}
\hline \multirow{2}{*}{ Sample } & \multicolumn{6}{|c|}{ Color coordinate } & \multirow{2}{*}{ Chroma $\left(C^{*}\right)$} & \multirow{2}{*}{$\mathrm{DE}_{00}$} & \multirow{2}{*}{$\Delta L^{*}$} & \multirow{2}{*}{$\Delta a^{*}$} & \multirow{2}{*}{$\Delta b^{*}$} & \multirow{2}{*}{$\Delta \mathrm{DE}_{00}$} \\
\hline & $Y$ & $x$ & $y$ & $L^{*}$ & $a^{*}$ & $b^{*}$ & & & & & & \\
\hline S1 & 30.935 & 0.577 & 0.371 & 62.452 & 52.263 & 50.530 & 72.71 & 0 & - & - & - & - \\
\hline S2 & 16.521 & 0.458 & 0.366 & 47.651 & 26.696 & 25.834 & 37.14 & 17.35 & 14.801 & 25.567 & 24.696 & 17.35 \\
\hline S3 & 13.228 & 0.426 & 0.361 & 43.104 & 19.287 & 18.466 & 26.69 & 23.68 & 4.547 & 7.409 & 7.368 & 6.33 \\
\hline S4 & 10.788 & 0.399 & 0.354 & 39.227 & 14.140 & 12.822 & 19.08 & 29.05 & 3.877 & 5.147 & 5.644 & 5.37 \\
\hline S5 & 10.139 & 0.385 & 0.351 & 38.094 & 11.601 & 10.349 & 15.54 & 31.00 & 1.133 & 2.539 & 2.473 & 1.95 \\
\hline S6 & 8.425 & 0.377 & 0.349 & 34.858 & 9.590 & 8.676 & 12.92 & 34.22 & 3.236 & 2.011 & 1.673 & 3.22 \\
\hline S7 & 7.402 & 0.361 & 0.345 & 32.712 & 6.923 & 6.237 & 9.31 & 36.78 & 2.146 & 2.667 & 2.439 & 2.56 \\
\hline S8 & 6.625 & 0.350 & 0.343 & 30.944 & 4.977 & 4.770 & 6.89 & 38.66 & 1.768 & 1.946 & 1.467 & 1.88 \\
\hline S9 & 6.272 & 0.336 & 0.338 & 30.099 & 3.108 & 2.701 & 4.12 & 40.14 & 0.845 & 1.869 & 2.069 & 1.48 \\
\hline S10 & 5.650 & 0.327 & 0.336 & 28.512 & 1.782 & 1.633 & 2.42 & 41.65 & 1.587 & 1.326 & 1.068 & 1.51 \\
\hline S11 & 5.225 & 0.316 & 0.332 & 27.375 & 0.276 & 0.345 & 0.44 & 43.03 & 1.137 & 1.506 & 1.288 & 1.38 \\
\hline
\end{tabular}

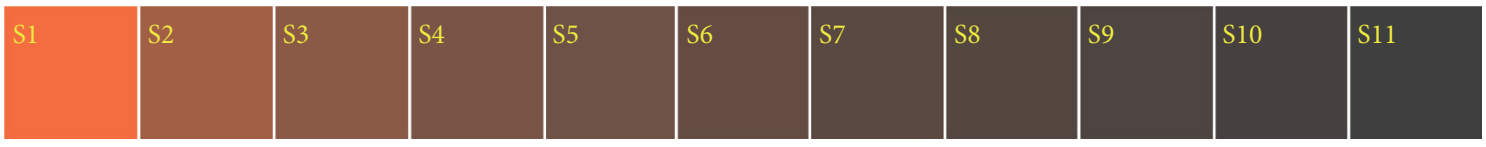

FIGURE 6: Simulating degradation samples.

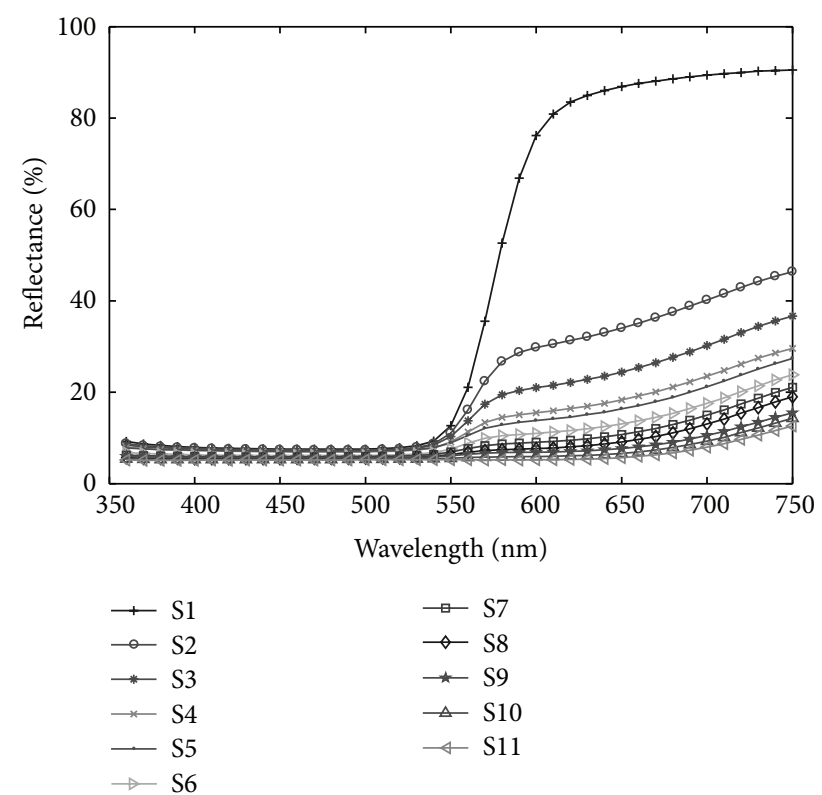

(a)

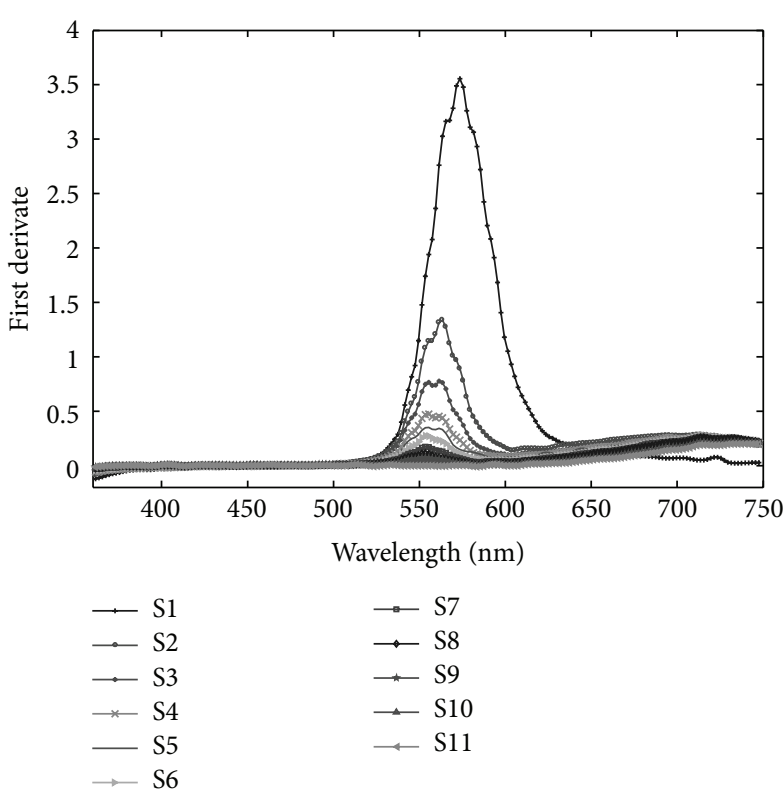

(b)

FIGURE 7: Distribution of the spectral reflectance of the simulating degradation samples (a) and the corresponding first derivate (b). 


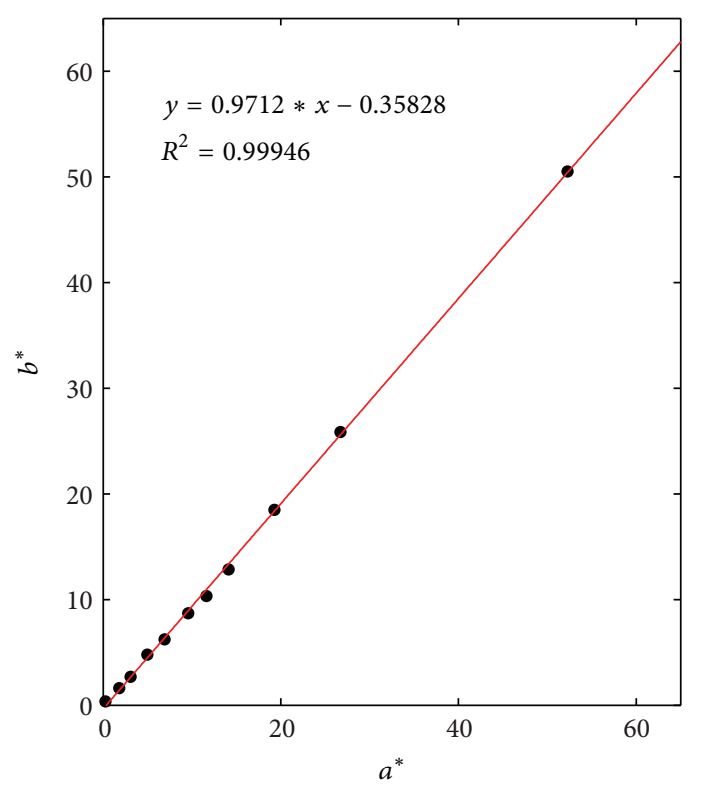

(a)

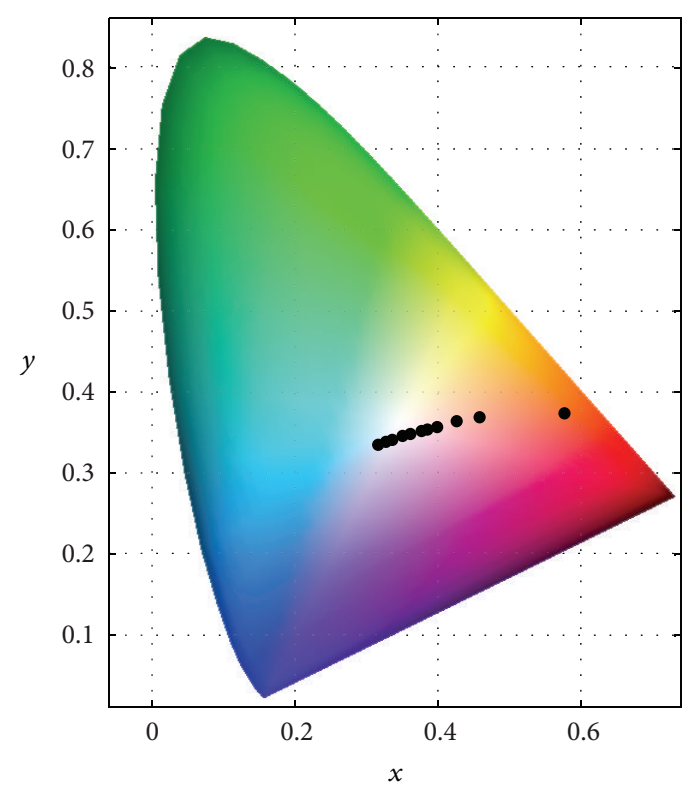

(b)

FIGURE 8: Hue distribution of the simulating degradation samples in $a^{*}-b^{*}$ planes (a) and CIE 1931 chromaticity diagram (b).

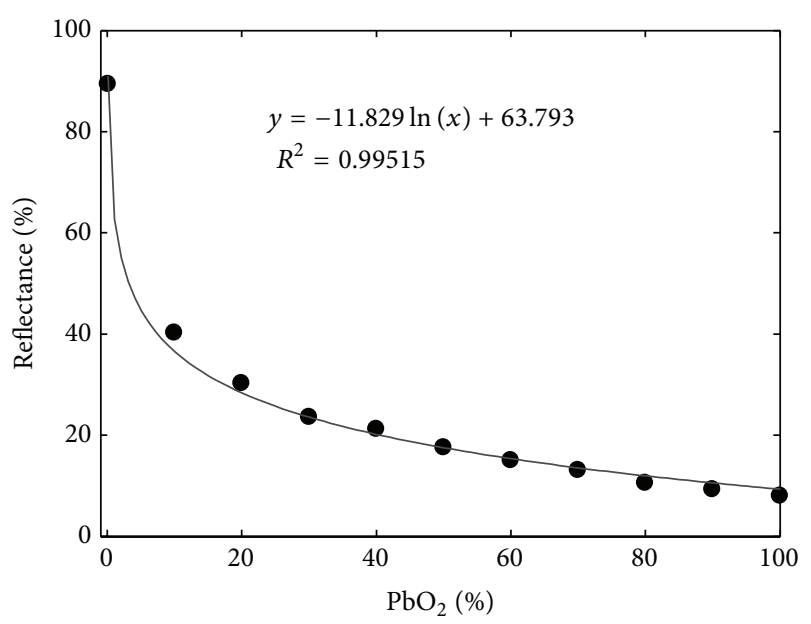

FIGURE 9: Decreasing trend of the spectral reflectance of the simulating degradation samples at $700 \mathrm{~nm}$.

simulating degradation samples was fitted with some simple linear or nonlinear functions. Here the mass ratio of lead dioxide in total mass was used to monitor the change of spectral reflectance. Figure 9 shows the decreasing trend of the spectral reflectance at $700 \mathrm{~nm}$. It can be seen from Figure 9 that the decreased trend could be fitted very well using the logarithmic model and that $R^{2}$ value of the fitting equation is high up to 0.99515 . Moreover, the average $R^{2}$ value from 560 to $750 \mathrm{~nm}$ is higher than 0.97 , and the minimum $R^{2}$ value is 0.95329 .

The other simple functions were also adopted to fit the changing trend of the simulating degradation samples. $R^{2}$ values of these fitting functions and the logarithmic fitting function are summarized in Table 7. $R^{2}$ values in Table 7 show
TABLE 7: $R^{2}$ values of different fitting functions at $700 \mathrm{~nm}$.

\begin{tabular}{lc}
\hline Functions & $R^{2}$ \\
\hline Exponential & 0.92245 \\
Linear & 0.63268 \\
Logarithmic & 0.99515 \\
Polynomial $(2)^{*}$ & 0.84378 \\
Power & 0.82483 \\
\hline
\end{tabular}

*Note: "polynomial (2)" represents the two-order polynomial.

that the logarithmic function has the highest accuracy which is consistent with the previous hypothesis. Furthermore, the decreasing trend in short-wavelength regions from 360 to $550 \mathrm{~nm}$ acquires the best fitting accuracy using the linear function. The fitting result shows that the average $R^{2}$ value from 360 to $550 \mathrm{~nm}$ is higher than 0.97 and the minimum $R^{2}$ value is 0.95993 . Thus the spectral discoloration model could be constructed with the abovementioned results. Besides, the spectral reflectance is regarded as the "fingerprint" of the object color and all the chromaticity values are calculated from the spectral reflectance under different illuminating and viewing conditions, so there is no need to construct the discoloration model in color space.

Based on the above analysis, the spectral discoloration model of red lead pigment was constructed as follows:

$$
Y_{i}= \begin{cases}A x+B, & (\text { if } 1 \leq i<22), \\ A \ln (x)+B, & (\text { if } 22 \leq i \leq 40),\end{cases}
$$

where $i$ represents the number of the sampling points from 360 to $750 \mathrm{~nm}$ at $10 \mathrm{~nm}$ intervals; $x$ is mass ratios of lead dioxide in the simulating degradation samples; $Y_{i}$ denotes 
the spectral reflectance in different sampling point for the specific $x$; and $A$ and $B$ contain the model parameters in each sampling wavelength from 360 to $750 \mathrm{~nm}$ at $10 \mathrm{~nm}$ interval; namely,

$$
\begin{gathered}
A=\left[\begin{array}{c}
A_{1} \\
\vdots \\
A_{i} \\
\vdots \\
A_{40}
\end{array}\right], \\
B=\left[\begin{array}{c}
B_{1} \\
\vdots \\
B_{i} \\
\vdots \\
B_{40}
\end{array}\right] .
\end{gathered}
$$

After the spectral discoloration model was constructed, its prediction accuracy was firstly examined by the simulating degradation samples with the known aging degree of $x$. The results show that the constructed spectral discoloration model is effective as the average spectral root-mean-square error, the average spectral goodness-of-fit coefficient [22], and the average color difference $\mathrm{DE}_{00}$ of the eleven simulation aging samples are all kept in a fairly good level at 0.0591, 0.9979 , and 1.14, respectively.

3.4. Real Aging Red Lead Pigment in Dunhuang Murals. The red lead pigment is widely used in Dunhuang murals, especially for the flesh of the Buddha in murals. Most of the murals painted with red lead pigment are black today. But there is still some incompletely discolored red lead pigment identified by chemical analysis of previous researchers $[8,23]$. Several red lead pigment points in different aging degree in two typical grottoes from different dynasties were measured with the in situ nondestructive measurement method. The validity of the model was verified by calculating and predicting the spectral reflectance of the real aging red lead pigment.

The PR705 spectroradiometer with the standard whiteboard produced by American Photo Research was used to measure the spectral reflectance of the real aging red lead pigment in Dunhuang murals, and the actual measured work scene is shown in Figure 10. The insert in Figure 10 represents the geometrical conditions of illumination and measurement. The points measured by PR705 spectroradiometer were marked in Figure 11. The measured spectral reflectance of the five marked points was plotted in Figure 12.

Because of the larger measurement noise in the shortwavelength below $400 \mathrm{~nm}$ and the long-wavelength above $700 \mathrm{~nm}$, the effective wavelength range of the sampled points was restricted to $400 \sim 700 \mathrm{~nm}$ as plotted in Figure 12. It can be seen that there is a very strong similarity between the spectral reflectance shapes of the real aging red lead pigment and the above two experiment samples. The hue distribution of the

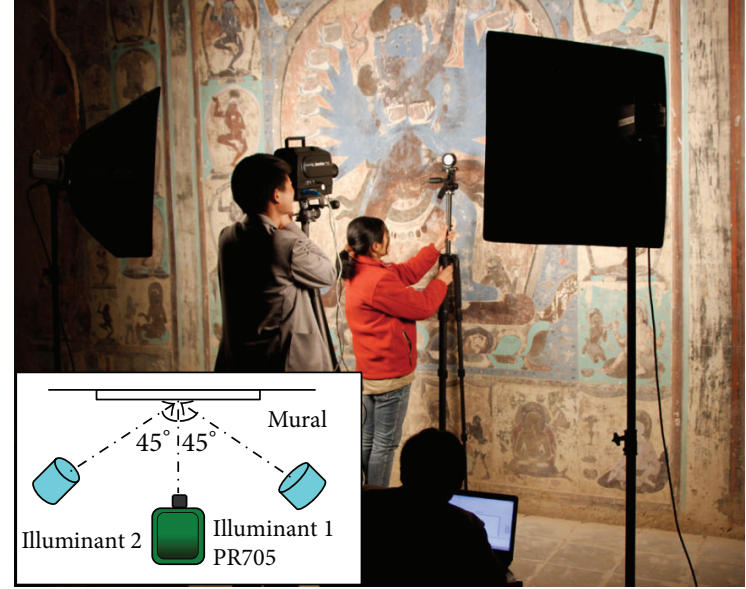

FIGURE 10: Spectral reflectance measured using PR705 spectroradiometer in cave 465 (Yuan Dynasty).

TABLE 8: The predicted accuracy of the five real aging red lead pigment points.

\begin{tabular}{lccc}
\hline Point number & RMS (\%) & $\mathrm{DE}_{00}$ & GFC (\%) \\
\hline 1 & 1.50 & 1.99 & 99.93 \\
2 & 1.30 & 3.24 & 99.59 \\
3 & 1.28 & 2.61 & 99.88 \\
4 & 1.14 & 2.87 & 99.86 \\
5 & 0.81 & 2.48 & 99.47 \\
\hline Mean & 1.21 & 2.64 & 99.75 \\
\hline
\end{tabular}

real aging red lead points also can be fitted well with the linear model with the slope, the intercept, and $R^{2}$ value being equal to $0.9692,0.5621$, and 0.9597 . Based on the constructed spectral discoloration model, the simulated aging degree of the five real aging red lead pigment points was calculated as $0.8028 \%, 31.4346 \%, 5.2151 \%, 9.7909 \%$, and $73.4961 \%$ using the inversed spectral discoloration model.

After the detection of aging degree, the spectral reflectance of the five points was predicted using the proposed spectral discoloration model as plotted in Figure 13 with the dash-dot line. The prediction accuracy was also evaluated by the metrics of spectral root-mean-square error, the spectral goodness-of-fit coefficient, and the color difference $\mathrm{DE}_{00}$. The predicted results of the five points are summarized in Table 8 . The average spectral root-meansquare error and color difference $\mathrm{DE}_{00}$ are $1.21 \%$ and 2.64 , respectively. The average spectral goodness-of-fit coefficient is high up to $99.75 \%$. The predicted results indicated that the constructed spectral discoloration model could well predict the spectral reflectance of the real aging red lead pigment in Dunhuang murals based on the simulated aging degree. It can be concluded that the constructed spectral discoloration model for red lead pigment could work well in detecting the aging degree of red lead pigment in ancient murals and reproducing the spectral data for specific aging degree. 


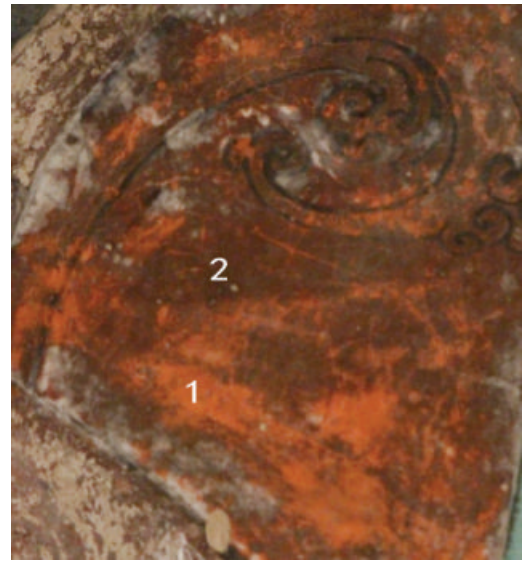

(a)

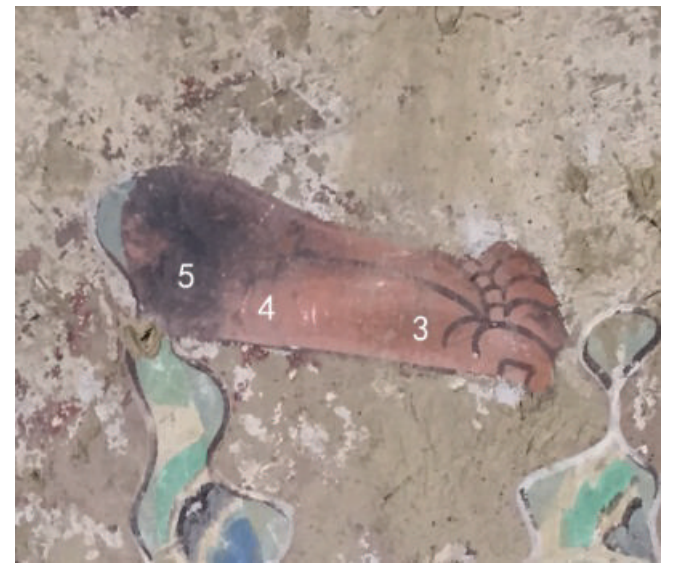

(b)

FIGURE 11: Five real aging red lead pigment points in Dunhuang murals: (a) Yuan Dynasty cave 465 and (b) Early Tang Dynasty cave 220.

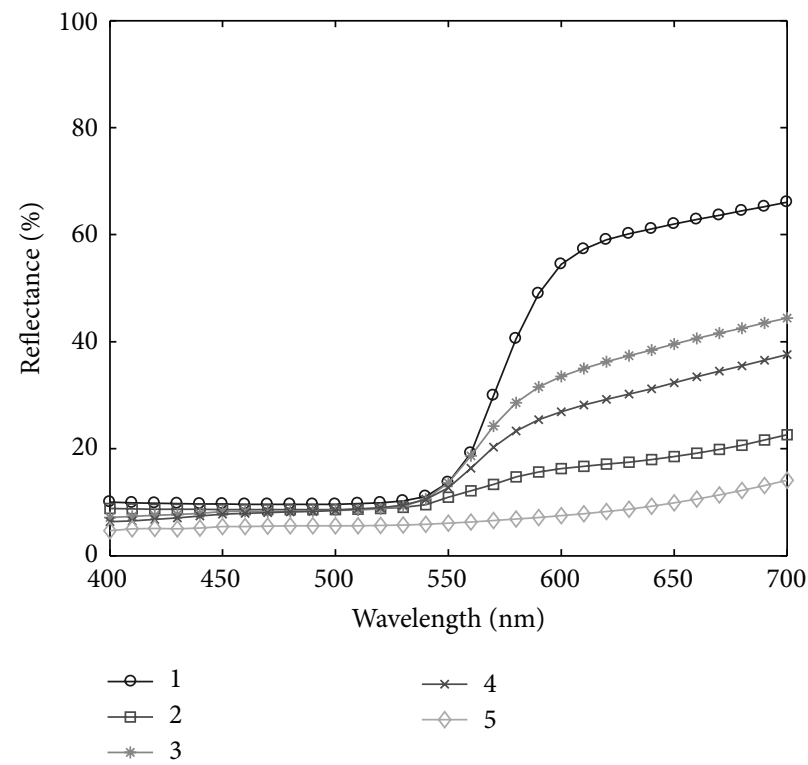

FIGURE 12: Distribution of spectral reflectance of the marked five points in the figure.
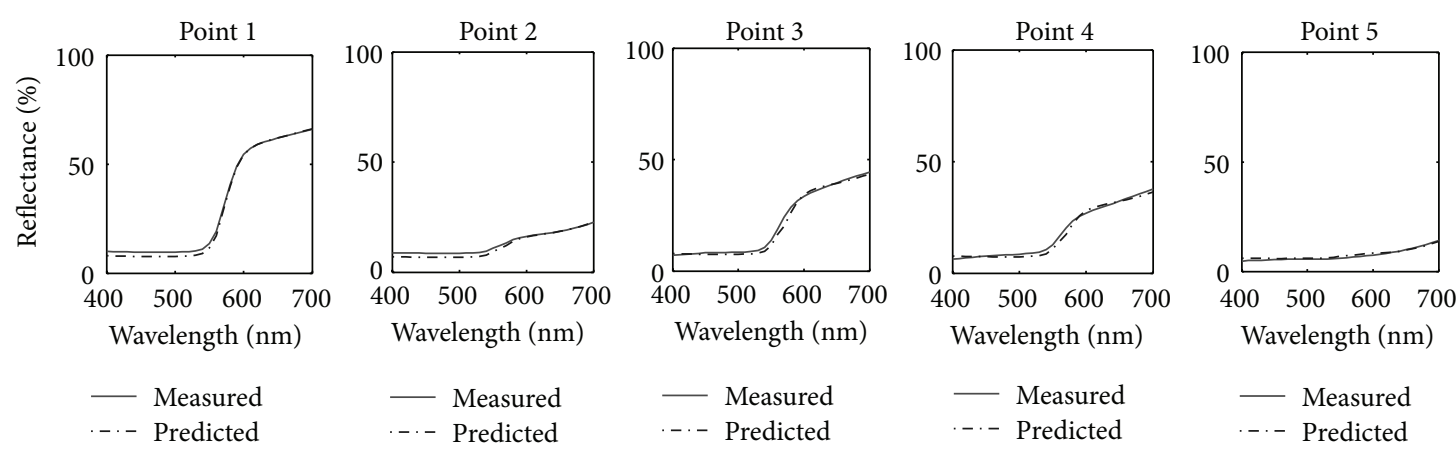

$$
\text { -..- Predicted }
$$

FIGURE 13: Measured (solid line) and predicted (dash-dot line) spectral reflectance of the five real aging red lead pigment points using the spectral discoloration model. 


\section{Conclusion}

A spectral discoloration model for the aging red lead pigment in Dunhuang murals was tentatively constructed to detect the aging degree of red lead pigment and to reproduce the spectral reflectance based on aging test and simulating degradation experiment. The chemistry and physical attributes of red lead pigment during its aging process under the aging conditions were characterized, where the red lead was identified changing into lead dioxide and the amount of tiny particles increasing in the painted layer faced with the aging process. The spectral reflectance and chromaticity of the aging red lead pigment were analyzed and the spectral discoloration model was constructed to describe the red lead pigment aging process. The test results indicate that the constructed spectral discoloration model could be well applied to calculate the aging degree and to predict the spectral reflectance of red lead pigment in Dunhuang murals. Based on the constructed spectral discoloration model, the virtual restoration of the color of the darkened murals painted by red lead pigments will be more accurate and scientific.

\section{Competing Interests}

The authors declare that there are no competing interests regarding the publication of the paper.

\section{Acknowledgments}

This work was supported by the National Basic Research Program of China (973 Program) (Grant no. 2012CB725302) and the National Natural Science Foundation of China (Grant nos. 61275172, and 61575147).

\section{References}

[1] S. Aze, J.-M. Vallet, V. Detalle, O. Grauby, and A. Baronnet, "Chromatic alterations of red lead pigments in artworks: a review," Phase Transitions, vol. 81, no. 2-3, pp. 145-154, 2008.

[2] S. Daniilia and E. Minopoulou, "A study of smalt and red lead discolouration in Antiphonitis wall paintings in Cyprus," Applied Physics A: Materials Science and Processing, vol. 96, no. 3, pp. 701-711, 2009.

[3] J. Olszewska-Świetlik, B. Szmelter-Fausek, E. Pięta, and E. Proniewicz, "Spectroscopic and gas chromatographic studies of pigments and binders in Gdańsk paintings of the 17th century," Journal of Spectroscopy, vol. 2013, Article ID 187407, 8 pages, 2013.

[4] C. Miguel, A. Claro, A. P. Gonçalves, V. S. F. Muralha, and M. J. Melo, "A study on red lead degradation in a medieval manuscript Lorvão Apocalypse (1189)," Journal of Raman Spectroscopy, vol. 40, no. 12, pp. 1966-1973, 2009.

[5] M. Kitada, "Microstructure and discoloration of red lead pigment used for wood-block-printed book Kodouzuroku of the late Edo period," Journal of the Japan Institute of Metals, vol. 71, no. 10, pp. 921-926, 2007.

[6] A. Doménech-Carbó, M. T. Doménech-Carbó, M. MoyaMoreno, J. V. Gimeno-Adelantado, and F. Bosch-Reig, "Identification of inorganic pigments from paintings and polychromed sculptures immobilized into polymer film electrodes by stripping differential pulse voltammetry," Analytica Chimica Acta, vol. 407, no. 1-2, pp. 275-289, 2000.

[7] E. Uchida, Y. Takubo, K. Toyouchi, and J. Miyata, "Study on the pigments in the cruciform gallery of Angkor Wat, Cambodia," Archaeometry, vol. 54, no. 3, pp. 549-564, 2012.

[8] R. J. Wu, "Chromatic applying of dunhuang murals and the cause of color changes," Dunhuang Research, no. 5, pp. 44-50, 2003 (Chinese).

[9] S. Aze, J.-M. Vallet, M. Pomey, A. Baronnet, and O. Grauby, "Red lead darkening in wall paintings: natural ageing of experimental wall paintings versus artificial ageing tests," European Journal of Mineralogy, vol. 19, no. 6, pp. 883-890, 2007.

[10] J. Qu, S. Cao, G. Li, Q. Niu, and Q. Feng, "Conservation of natural and cultural heritage in Dunhuang, China," Gondwana Research, vol. 26, no. 3-4, pp. 1216-1221, 2014.

[11] X. Shi and D. Lu, "Colorimetric and chemical modeling based aging simulation of Dunhuang murals," in Proceedings of the 5th International Conference on Computer and Information Technology (CIT '05), pp. 570-574, IEEE, Shanghai, China, 2005.

[12] X. Shi, D. Lu, and J. Liu, "Color changing and fading simulation for frescoes based on empirical knowledge from artists," in Advances in Multimedia Information Processing-PCM 2006, Y. Zhuang, S.-Q. Yang, Y. Rui, and Q. He, Eds., vol. 4261 of Lecture Notes in Computer Science, pp. 861-869, Springer, Berlin, Germany, 2006.

[13] Y. Zhao, Y. Tang, T. Tong et al., "Red lead degradation: monitoring of color change over time," New Journal of Chemistry, vol. 40, no. 4, pp. 3686-3692, 2016.

[14] X. Zhang, B. Funt, and H. Mirzaei, "Metamer mismatching in practice versus theory," Journal of the Optical Society of America A, vol. 33, no. 3, pp. A238-A247, 2016.

[15] M. Kubik, "Hyperspectral imaging: a new technique for the non-invasive study of artworks," Physical Techniques in the Study of Art, Archaeology and Cultural Heritage, no. 2, pp. 199-259, 2007.

[16] M. Elias and P. Cotte, "Multispectral camera and radiative transfer equation used to depict Leonardo's sfumato in Mona Lisa," Applied Optics, vol. 47, no. 12, pp. 2146-2154, 2008.

[17] A. Cosentino, "Identification of pigments by multispectral imaging; a flowchart method," Heritage Science, vol. 2, no. 8, pp. $1-12,2014$.

[18] G. Wyszecki and W. S. Stiles, Color Science, vol. 8, John Wiley \& Sons, New York, NY, USA, 1982.

[19] J. Wagberg, January 2007, http://cn.mathworks.com/matlabcent -ral/fileexchange/13788-optprop-a-color-properties-toolbox.

[20] G. Sharma, W. Wu, and E. N. Dalal, "The CIEDE2000 colordifference formula: implementation notes, supplementary test data, and mathematical observations," Color Research \& Application, vol. 30, no. 1, pp. 21-30, 2005.

[21] Z. Li, "A study on the ageing of the cementing material in Dunhuang Murals," Dunhuang Research, no. 3, pp. 75-89, 1990 (Chinese).

[22] R. Shrestha, R. Pillay, S. George, and J. Y. Hardeberg, "Quality evaluation in spectral imaging-quality factors and metrics," Journal of the International Colour Association, no. 12, pp. 2235, 2014.

[23] F. Sheng, Z. Li, and Z. Fan, "Humidity is the main cause for discoloration of minium," Dunhuang Research, no. 4, pp. 98-113, 1990 (Chinese). 

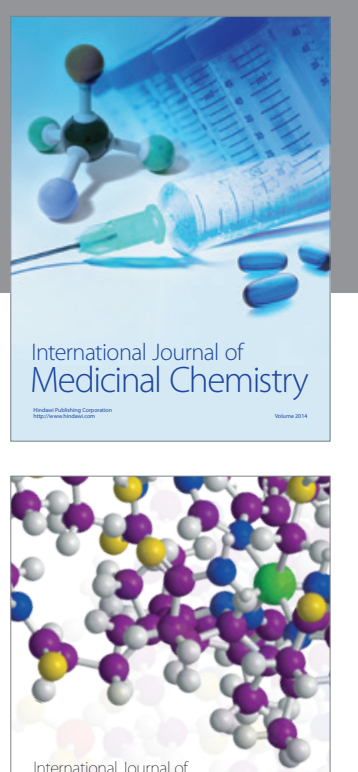

Carbohydrate Chemistry

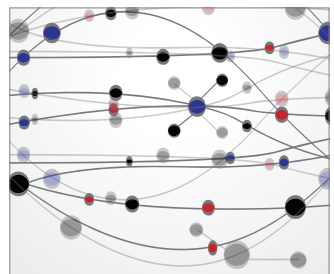

The Scientific World Journal
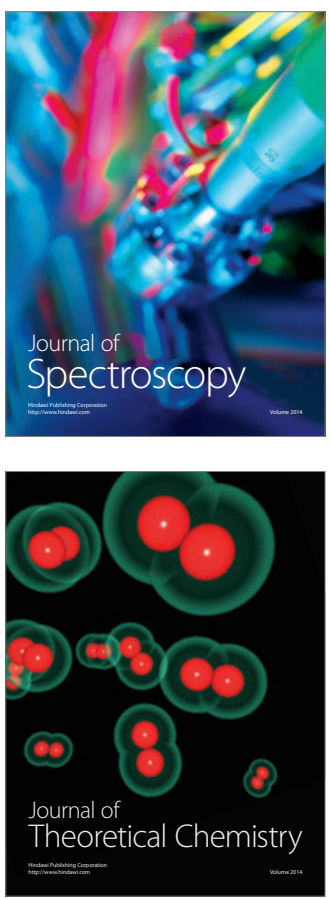
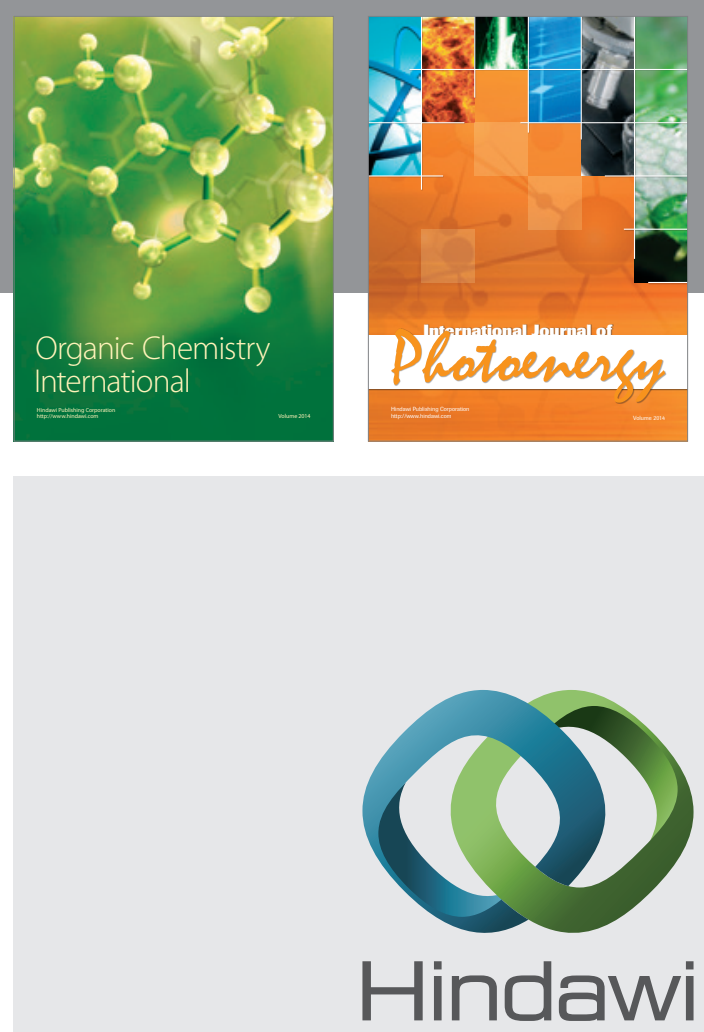

Submit your manuscripts at

http://www.hindawi.com

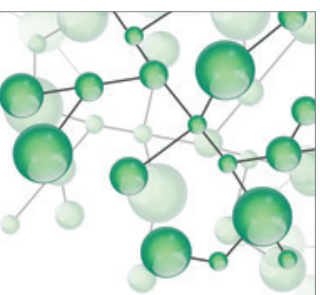

International Journal of

Inorganic Chemistry

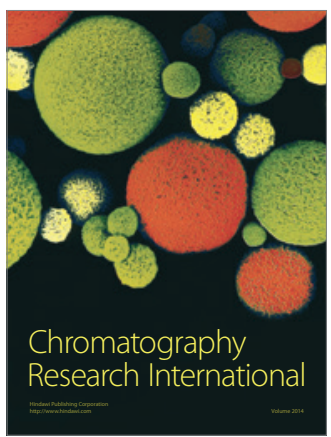

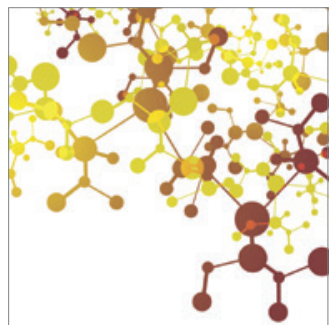

Applied Chemistry
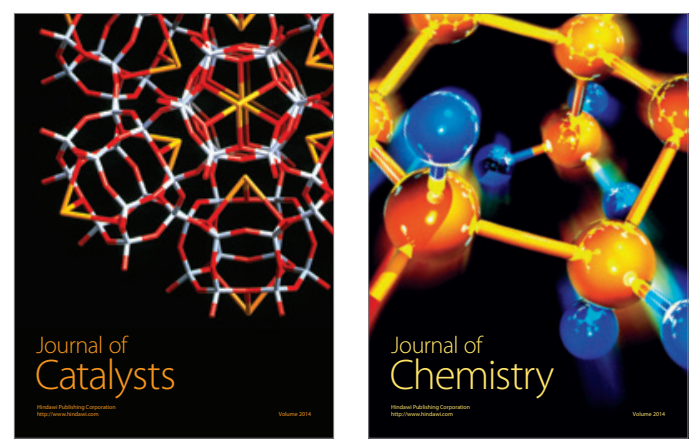
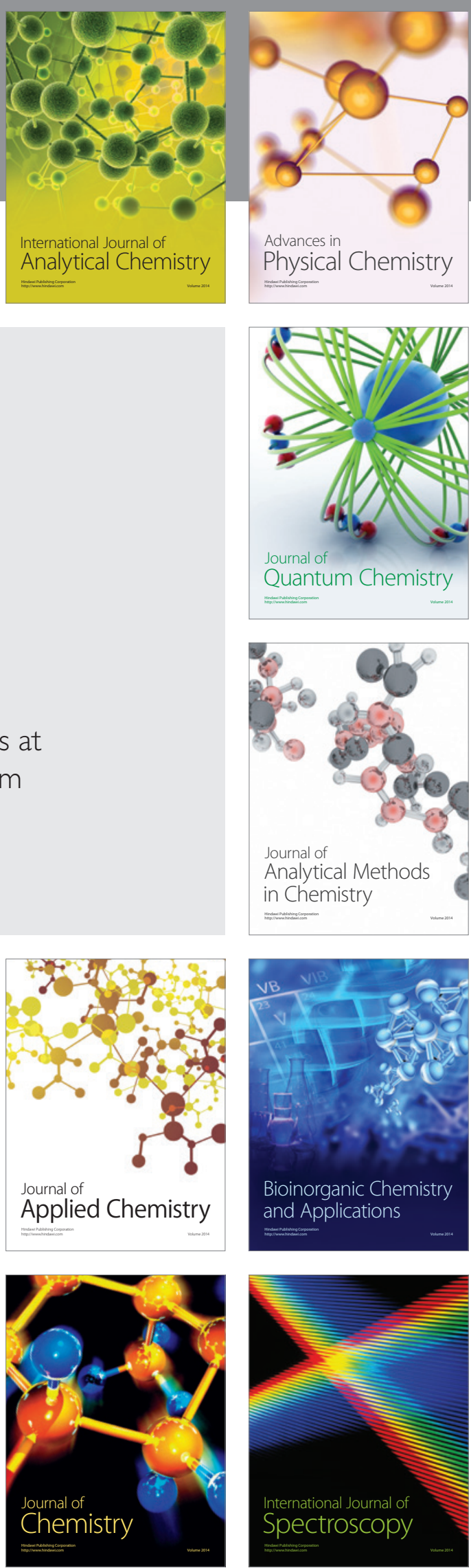